\title{
Chemical Reaction and Thermal Radiation Effects on Magnetohydrodynamic Nanofluid Flow Past an Exponentially Stretching Sheet
}

\author{
Uchenna Awucha Uka ${ }^{*}$, Emeka Amos ${ }^{2}$ and Chinedu Nwaigwe ${ }^{3}$
}

\begin{abstract}
This study investigates chemical reaction and thermal radiation effects on hydromagnetic nanofluid flow over an exponentially stretching sheet. The governing partial differential equations were transformed to ordinary differential equations by using similarity transformation and the resulting equations were solved using asymptotic series method. Graphical results showing the influence of the governing parameters on the velocity, temperature and concentration are displayed. Our results indicated that an increase in stretching sheet, thermal Grashof parameters leads to the increase in the rate of fluid flow while it decreases when magnetic field factor is increased. Also, increasing the thermophoresis number brings about increase in temperature and concentration while the reverse is the case as Prandtl number, Schmidt factor and chemical reaction rate increases. Increase in radiation leads to increase in the temperature.
\end{abstract}

Keywords: Thermophoresis, Stretching sheet, MHD (Magnetohydrodynamic), thermal Radiation, Chemical reaction, Nanofluid.

\footnotetext{
${ }^{1}$ Department of Basic Sciences, Babcock University, Ilishan-Remo, Ogun State, Nigeria.

*Corresponding Author

2 Department of Mathematics, Rivers State University, Port Harcourt, Nigeria.

3 Department of Mathematics, Rivers State University, Port Harcourt, Nigeria.
} 


\section{Introduction}

The study of magnetohydrodynamic nanofluid flow over an exponentially stretching sheet exhibits several healthy applications in science and technology, industrial appliances, electronic gadgets, automobile industries, etc. However, the areas of application and usefulness of this study is vast and include nuclear reactor fluidization: In order to have effective cooling process in the reactors of nuclear fission, electromagnetic forces are used to supply liquified sodium around the reactors, cooling of an infinite hot metal sheet in a cooling tub, rubber sheets and plastic production, drawing of cables and fiber sheets, etc. Thermal as well as mass transmission in Carreau fluid broadens the importance and useful applications in sciences such as physiology, symptoms of neurology, treatment of diagnostic diseases etc. However, it is important to mention that although nanofluid (Nano suspension) is made up of two parts which are the base fluid and solid particles, "surfactant" is added in some cases in order to elongate the stability of the mixture. (Sheremet and Pop, 2015), investigated steady-state free convection in a medium containing pore having nanofluid, couple energy transference and Buongiorno's model. They noted that the local Nusselt number rises with a rise in Rayleigh number and buoyancy ratio index.

According to (Chen, 1998) an investigation was carried on the motion of fluid and thermal transmission over a surface that is elongated was done. A modification on this study was carried out as reported by (Ishak et al., 2008). It was noted that such physical parameters of interest decline when magnetic force/strength rises.

The analysis of magnetohydrodynamic Casson fluid over a stretching surface past spongy material indicated that the rate of fluid movement retards because of the drag force produced by transverse magnetic source (Nadeem et al., 2013).

The study of flow over boundary layer past a strong sheet in motion in the presence of non-varying velocity was championed by (Sakiadis, 1961). His work was revisited through the introduction of a extending material in a linear motion from a non-movable position as given by (Crane, 1970).

Techniques to control flow means a little deviation representing perfectly a great application in field of Engineering such as haul decrease, hoist rise, blending upliftment (Wikipedia, the free encyclopedia, 2017).

However, (Sheremet and Pop, 2014), carried out study on the two-dimensional nonturbulence free convection of water-based fluids in a double porous hollow such that lateral parapets possess sinusoidal parapet degree of coldness or hotness by using Buongiorno's model. They resolved from their findings that with a slight Lewis number is slight, and increased value of thermophoresis, the heterogeneous smaller particles dispersion in the fluid will be more physical.

Analysis of the impact of different nanoparticles on transmission of heat as a result of impartation of temperature gradient over a thermally medium. It was reported that transmission of heat energy is well pronounced (Oztop and Abu-Nada, 2008). (Santoshi and Govardhan, 2020), considered the influence of magnetic strength, heat source/sink in nanofluid past a permeable elongating surface with external heat 
energy and non-complete slide. (Rohana, 2014) examined the magnetohydrodynamic Marangonic convective nanofluid in the presence of injection and blowing. Verification of magnetohydrodynamics boundary layer passage of thermal cum mass transmission past upright material in motion, chemically reacting in presence of suction by (Ibrahim and Makinde, 2010) was noted. Indications from their findings depicts that rate of fluid motion suppresses as temperature and concentration elevates.

Studies abound on the influence of thermal radiation on fluid flows and the results obtained have been significant, (Raptis et al., 2004), (Mabood et al., 2017), (Devi and Reddy, 2014), (Bunonyo et al., 2018) and (Omamoke et al., 2020) just to mention but a few. However, influence of radiation, viscosity on MHD non-steady natural flow past a partially sieve-like material was analyzed by (Joaquin, 2007). The influence of radiative temperature on nanofluid movements instigated via a radically overextended exterior through flexible viscidness was reported by (Makinde et al., 2016) and they found that resistance issue appreciates by means of convective constraint. (Raju et al., 2016), categorized the impacts of hotness and mass conveyance on magnetohydrodynamic movement past an enlarging surface. From their study, exponential factor has tendency to elevate the degree of fluid movement. Meanwhile, (Irfan et al., 2019) considered the magnetohydrodynamic free stream and heat transfer of nanofluid flow over an exponentially radiating stretching sheet with variable fluid properties. They opined that thermal boundary coating stiffness rises as the thermal conductivity, viscosity of fluid, Brownian motion and Thermophoresis numbers intensify.

However, as a result of the numerous applications of nanofluid flow over a stretching surface, many researchers and scientists have been attracted to its study. It's also imperative to remark that magnetohydrodynamic fluids possess the characteristics of electromagnetic conductivity which is very important as long as flow and heat transfer is concerned. Nevertheless, the application of this concept in areas of modern technological advancement has really been shown to be very useful to humans. For example, in the satellite and solar power industries, medical fields, etc. with regards to the medical field, the nanoparticles made of gold are used in the manufacturing and distribution of medicine for the treatment of tumors of cancer in the body (Bouslimi et al., 2021).

(Dandpat and Chakraborthy, 2010), analyzed the outcome of changeable fluid factors on tinny liquid motion picture flow over an instable intense widening sheet. They noted that the consequence of inconstant fluid thickness on the profile of the velocity enhances as viscosity decreases as a result of temperature decrease on the stretching plate. (Hsiao, 2001), investigated the magneto-hydrodynamic inaction point passage of visco-elastic fluid on thermal making stretching sheet with the effect of viscid degeneracy. They opined that as the magnetic parameter upsurges, the proportion of assignment of heat energy falls. However, analysis of the flow over a shaky elongating surface with chemical reaction and unequal heat origin by applying Runge-Kutta-Fehlberg technique and shooting approaches was carried out by (Seini, 2013). It was indicated that the amount of transmission of heat and mass 
together with the coefficient of the skin friction enhances with an enhancement of the unsteadiness factor but retards with an enhancement of the space-dependent and temperature-dependent factors.

Similarly, an investigation of magneto-hydrodynamic limit layer flow because of exponential stretching surface through radiation and chemical reaction by applying Runge-Kutta-Fehlberg technique and shooting approaches was executed by (Seini and Makinde, 2013). As a result of the magnetic parameter, the presence of a velocity term which appears nonlinear was found in the equation of the temperature of the model. Their results showed that the enhancement of the parameters of radiation as well as transverse magnetic field brings about to decrease in the transfer heat energy proportion on the surface. In the same vein, (Sahoo and Biswal, 2015), presented magneto-hydrodynamic viscoelastic boundary layer flow over a stretching surface in the presence of heat transfer. They indicated that increased values of Prandtl factor causes a gradual decay of temperature because of low thermal conductivity.

From the studies examined above, none of them investigated the influence of chemical reaction on the flow. Hence, we carry out our analysis on an exponentially stretching sheet in a hydromagnetic nanofluid, putting into consideration stretching material, convective terms, rate of chemical reaction, thermal conductivity and radiation.

\section{Mathematical Formulation}

We consider a steady dual-dimensional, electrically conducting, viscous, incompressible flow of nanofluid over a stretching sheet. The stretching sheet is along the $x$-axis while the $y$-axis is normal to it. The velocity components are $u, v$ along the $x-, y-$, axis respectively. The flow field is exposed to a magnetic field of strength $B_{0}$ in the path transverse to the surface of the stretching surface. We assume that the magnetic Reynolds number is small, hence the induced magnetic field is negligible and consequently considered only the applied magnetic field Meanwhile, the nanoparticles immersed in the base fluid are influenced as a result of Brownian motion. The temperature, $T$ and nanoparticles volume fraction $\mathrm{C}$ at the boundary $(y=0)$ are $T_{w}$ and $C_{w}$ respectively while far from the plate the temperature and nanoparticles fraction are $T_{\infty}$ and $C_{\infty}$ respectively. Therefore, the boundary layer equations governing the present study are presented as follows:

$$
\begin{aligned}
& \frac{\partial u}{\partial x}+\frac{\partial v}{\partial y}=0 \\
& u \frac{\partial u}{\partial x}+v \frac{\partial u}{\partial y}=u_{\infty} \frac{d u_{\infty}}{d x}+\frac{1}{\rho} \frac{\partial}{\partial y}\left(\frac{\mu \partial u}{\partial y}\right)-\frac{\sigma B^{2}}{\rho}\left(u-u_{\infty}\right)+\frac{g \beta_{T} l^{3}\left(T-T_{\infty}\right)}{v^{2}}
\end{aligned}
$$




$$
\begin{aligned}
& u \frac{\partial T}{\partial x}+v \frac{\partial T}{\partial y}=\frac{1}{\rho c_{p}} \frac{\partial}{\partial y}\left(\frac{k \partial T}{\partial y}\right)+\tau \frac{D_{B}\left(C-C_{\infty}\right)}{D_{T} T_{\infty}}-\frac{1}{\rho c_{p}} \frac{\partial q_{r}}{\partial y} \\
& u \frac{\partial C}{\partial x}+v \frac{\partial C}{\partial y}=D_{B} \frac{\partial^{2} C}{\partial y^{2}}+\frac{D_{T}}{T_{\infty}}\left(T-T_{\infty}\right)-k r\left(C-C_{\infty}\right)
\end{aligned}
$$

Subjected to the following boundary conditions:

$$
\begin{aligned}
& u=U_{w}(x)=a e^{\frac{x}{L}}, v=-v_{w}, T=T_{w}, C=C_{w} \text { at } \quad y=0 \\
& u \rightarrow U_{\infty}(x)=b e^{\frac{x}{L}}, T \rightarrow T_{\infty}, C \rightarrow C_{\infty} \quad \text { as } \quad y \rightarrow \infty
\end{aligned}
$$

The similarity transformation variables are defined as follows:

$$
\begin{aligned}
& \eta=\sqrt{\frac{a}{2 v L}} e^{\frac{x}{2 L}} y, \varphi=\sqrt{2 v L a} e^{\frac{x}{2 L}} f(\eta), \theta=\frac{T-T_{\infty}}{T_{w}-T_{\infty}}, \quad \emptyset=\frac{C-C_{\infty}}{C_{w}-C_{\infty}}, \\
& u=\frac{\partial \psi}{\partial y}, \quad v=-\frac{\partial \psi}{\partial x}
\end{aligned}
$$

where, $\rho_{p}$ is the nanoparticle density, $\rho_{f}$ is the base fluid density, $\beta$ is volumetric thermal expansion coefficient of the base fluid, $\sigma$ is electrical conductivity parameter, $g$ is the acceleration due to gravity, $k$ is thermal conductivity, $\mu$ is viscosity of the fluid, $D_{T}$ is thermophoresis diffusion parameter, $k_{r}$ is the chemical reaction factor.

\section{Method of solution}

In order to solve the problem, we shall use the variables stated in equation (6) to transform equations (1) - (4) to have:

$$
\begin{gathered}
f^{\prime \prime \prime}(\eta)+2\left(\lambda^{2}-\left(f^{\prime}\right)^{2}(\eta)\right)+f(\eta) f^{\prime \prime}(\eta)-M\left(f^{\prime}(\eta)-\lambda\right)+\operatorname{Gr} \theta(\eta)=0 \\
\left(1+\frac{4 R}{3}\right) \theta^{\prime \prime}(\eta)+\operatorname{Pr}\left[\left(f(\eta) \theta^{\prime}(\eta)+f^{\prime}(\eta) \theta(\eta)\right)\right]+\frac{N_{b}}{N_{t}} W(\eta)=0 \\
W^{\prime \prime}(\eta)+\frac{N_{t}}{N_{b}} \theta(\eta)+S c\left(f(\eta) W^{\prime}(\eta)-f^{\prime}(\eta) W(\eta)-\gamma S c W(\eta)\right)=0
\end{gathered}
$$

Similarly, the transformed boundary conditions for the second model are:

$$
\begin{aligned}
& f(0)=h_{0}, f^{\prime}(0)=1, \theta(\eta)=1, \phi(0)=1 \text { at } \eta=0 \\
& f^{\prime}(\infty)=\lambda, \theta(\infty) \rightarrow 0, \phi(\infty) \rightarrow 0 \text { as } \eta \rightarrow \infty
\end{aligned}
$$


where, $M=\frac{2 \sigma B^{2} L}{\rho U_{w}}$, magnetic parameter, $\lambda=\frac{b}{a}$, stretching sheet factor, $G r=\frac{g \beta_{T} l^{3}\left(T_{w}-T_{\infty}\right)}{\left(U_{w} v\right)^{2}}$, is the thermal Grashof number, $\operatorname{Pr}=\frac{\mu c_{p}}{k}$, is the Prandtl number, $\tau=\frac{\left(\rho c_{p}\right)_{p}}{\left(\rho c_{p}\right)_{f}}$, is ratio of the specific heat capacities of the nanoparticle to that of the base fluid, $R=\frac{4 T_{\infty}^{3} \sigma^{*}}{3 k^{*} k}$, radiation parameter, $N_{b}=\frac{2 \tau D_{B}\left(C_{w}-C_{\infty}\right)}{k U_{w}}$, is Brownian motion factor, $N_{t}=\frac{2 \tau D_{T}\left(T_{w}-T_{\infty}\right)}{v T_{\infty} l}$, is thermophoresis factor, $S c=\frac{v}{D_{B}}$ is Schmidt number, $\gamma=\frac{2 L k r}{U_{w}}=$ modified chemical reaction rate, and the primes represent differentiation with respect to $\eta, h_{0}=\frac{v_{w}}{\sqrt{\frac{a v}{2 L}}}$ is the suction parameter.

In order to solve equations (7)-(9) with boundary equation (10), we follow (Bestman, 1990), thus,

$$
\eta=\Omega h_{0}, h(\eta)=h_{0} H(\eta), \theta(\eta)=\Theta(\eta), w(\eta)=\Psi(\eta), \varepsilon=\frac{1}{h_{0}^{2}}
$$

and the resulting set of equations are

$H^{\prime \prime \prime}(\eta)+2 \lambda^{2} \varepsilon^{2}-2\left(H^{\prime}\right)^{2}(\eta)+H(\eta) H^{\prime \prime}(\eta)-M H^{\prime}(\eta) \varepsilon+M \lambda \varepsilon^{2}+\varepsilon^{2} G r \Theta(\eta)=0$

$$
\begin{aligned}
& \Theta^{\prime \prime}(\eta)+\Theta^{\prime \prime}(\eta) \frac{4}{3} R+\operatorname{Pr} H(\eta) \Theta^{\prime}(\eta)+\operatorname{Pr} H^{\prime}(\eta) \Theta(\eta)+\varepsilon \frac{N t}{N b} \Psi(\eta)=0 \\
& \Psi^{\prime \prime}(\eta)+\varepsilon \frac{N_{t}}{N_{b}} \Theta(\eta)+H(\eta) \Psi^{\prime}(\eta) S c-H^{\prime}(\eta) \Psi(\eta) S c-\varepsilon \gamma S c \Psi(\eta)=0
\end{aligned}
$$

Subject to:

$H(0)=1, H^{\prime}(0)=\varepsilon, H^{\prime}(\infty)=\varepsilon \lambda, \Theta(0)=1, \Theta(\infty)=0, \Psi(0)=1, \Psi(\infty)=0$

With $\varepsilon<<1$, we shall solve the equation by adopting the asymptotic series technique, Bestman (1990):

$$
\begin{aligned}
& H(\eta)=1+\varepsilon H_{1}(\eta)+\varepsilon^{2} H_{2}(\eta)+\cdots \\
& \Theta(\eta)=\Theta_{0}(\eta)+\varepsilon \Theta_{1}(\eta)+\cdots \\
& \Psi(\eta)=\Psi_{0}(\eta)+\varepsilon \Psi_{1}(\eta)+\cdots
\end{aligned}
$$


Using equations (12) - (14) on equations (16) - (18) and after differentiations and simplification we obtain the series of approximations as:

$$
\begin{aligned}
& \left(1+\frac{4}{3} R\right) \Theta_{0}^{\prime \prime}(\eta)+\operatorname{Pr} \Theta(\eta)=0 \\
& \Psi_{0}^{\prime \prime}(\eta)+S_{c} \Psi_{1}^{\prime}(\eta)=0 \\
& H_{1}^{\prime \prime \prime}(\eta)+H_{1}^{\prime \prime}(\eta)=0 \\
& \left(1+\frac{4}{3} R\right) \Theta_{1}^{\prime \prime}(\eta)+\operatorname{Pr} \Theta_{1}^{\prime}(\eta)+\operatorname{Pr}_{1}(\eta) \Theta_{0}^{\prime}(\eta)+\operatorname{Pr} H_{1}^{\prime}(\eta) \Theta_{0}(\eta)+\frac{N t}{N b} \Psi_{0}(\eta)=0 \\
& \Psi_{1}^{\prime \prime}(\eta)+S_{c} \Psi_{1}^{\prime}(\eta)+H_{1}(\eta) \Psi_{0}^{\prime}(\eta) S c+H_{1}^{\prime}(\eta) \Psi_{0}(\eta) S c+\frac{N t}{N b} \Theta_{0}(\eta)-\gamma S_{c} \Psi_{0}(\eta)=0
\end{aligned}
$$

$H_{2}^{\prime \prime}(\eta)+2 \lambda^{2}-2\left(H_{1}^{\prime}\right)^{2}+(\eta)+H_{2}^{\prime \prime}(\eta)+H_{1}(\eta) H_{1}^{\prime \prime}(\eta)-M H_{1}^{\prime}(\eta)+M \lambda+G r \Theta(\eta)=$ $0(24)$

Subject to:

$\Theta_{0}(0)=1, \Theta_{0}(\infty)=0, \Psi_{0}(0)=1, \Psi_{0}(\infty)=0, H_{1}(0)=0, H_{1}^{\prime}(0)=1, H_{1}^{\prime}(\infty)=\lambda$

$\Theta_{1}(0)=0, \Theta_{1}(\infty)=0, \Psi_{1}(0)=0, \Psi_{1}(\infty)=0, H_{2}(0)=0, H_{2}^{\prime}(0)=0, H_{2}^{\prime}(\infty)=0$

Thus, solving equations (19) - (24) subject to equation (25), we have the following solutions:

$$
\begin{aligned}
& h^{\prime}(\eta)=\left(\lambda \eta-\lambda+1+\lambda e^{-\eta}-e^{-\eta}\right)-\left(4(\lambda)^{2} \eta e^{-\eta}-4 \lambda \eta e^{-\eta}-\lambda e^{-2 \eta}+\right. \\
& \frac{(\lambda)^{2}}{2} e^{-2 \eta}+\frac{1}{2} e^{-2 \eta}+M \lambda \eta e^{-\eta}-M \eta e^{-\eta}+\frac{C_{1} \lambda}{2}(\eta)^{2} e^{-\eta}+C_{1} \lambda \eta e^{-\eta}+C_{2} \lambda \eta e^{-\eta}- \\
& \frac{C_{3} \lambda}{4} e^{-2 \eta}-\frac{C_{1}}{2}(\eta)^{2} e^{-\eta}-C_{1} \eta e^{-\eta}-C_{2} \eta e^{-\eta}+\frac{C_{3}}{4} e^{-2 \eta}-\frac{G r}{q(q-1)} e^{-q \eta}-\frac{(\lambda)^{2}}{2}+3 \lambda- \\
& M \lambda+M-C_{1} \lambda-C_{2} \lambda-\frac{C_{3} \lambda}{2}+C_{1}+C_{2}+\frac{C_{3}}{4}-\frac{G r}{q-1}+\frac{1}{2}+\frac{G r}{q(q-1)}-\left(3(\lambda)^{2}-2 \lambda-\right. \\
& \left.\left.1+M \lambda-M+C_{1} \lambda+C_{2} \lambda+\frac{C_{3} \lambda}{2}-C_{1}-C_{2}-\frac{C_{3}}{2}+\frac{G r}{q-1}\right) e^{-\eta}\right)
\end{aligned}
$$

Where,

$$
C_{1}=\lambda
$$




$$
\begin{aligned}
& C_{2}=1 \\
& C_{3}=\lambda-1 \\
& \Theta(\eta)=e^{-q \eta}+\left(-\frac{q \lambda}{2}(\eta)^{2} e^{-q \eta}+q \lambda \eta e^{-q \eta}-q \eta e^{-q \eta}+\frac{(q)^{2} \lambda}{1+q} e^{-(1+q) \eta}-\right. \\
& \frac{(q)^{2}}{1+q} e^{-(1+q) \eta}+\frac{q \lambda}{1+q} e^{-(1+q) \eta}-\frac{q}{1+q} e^{-(1+q) \eta}-\frac{3 N t}{N b S c(3+4 R)(-q+S c)} e^{-S c \eta}- \\
& \left.\frac{(q)^{2} \lambda}{1+q} e^{-q \eta}+\frac{(q)^{2}}{1+q} e^{-q \eta}-\frac{q \lambda}{1+q} e^{-q \eta}+\frac{q}{1+q} e^{-q \eta}+\frac{3 N t}{N b S c(3+4 R)(S c-q)} e^{-q \eta}\right) \\
& \Psi(\eta)=e^{-S c \eta}+\frac{\lambda}{2}(\eta)^{2} e^{-S c \eta}-2 \lambda \eta e^{-S c \eta}+\eta e^{-S c \eta}-\frac{S c \lambda}{1+S c} e^{-(1+S c) \eta}+ \\
& \frac{S c}{1+S c} e^{-(1+S c) \eta}-\frac{S c \lambda}{1+S c} e^{-(1+S c) \eta}+\frac{S c}{1+S c} e^{-(1+S c) \eta}-\frac{N t}{N b q(q-S c)} e^{-q \eta}-\gamma \eta e^{-S c \eta}+ \\
& \frac{S c \lambda}{1+S c} e^{-S c \eta}-\frac{S c}{1+S c} e^{-S c \eta}+\frac{S c \lambda}{1+S c} e^{-S c \eta}-\frac{S c}{1+S c}+\frac{N t}{N b q(q-S c)} e^{-S c \eta}
\end{aligned}
$$

\section{Results and Discussion}

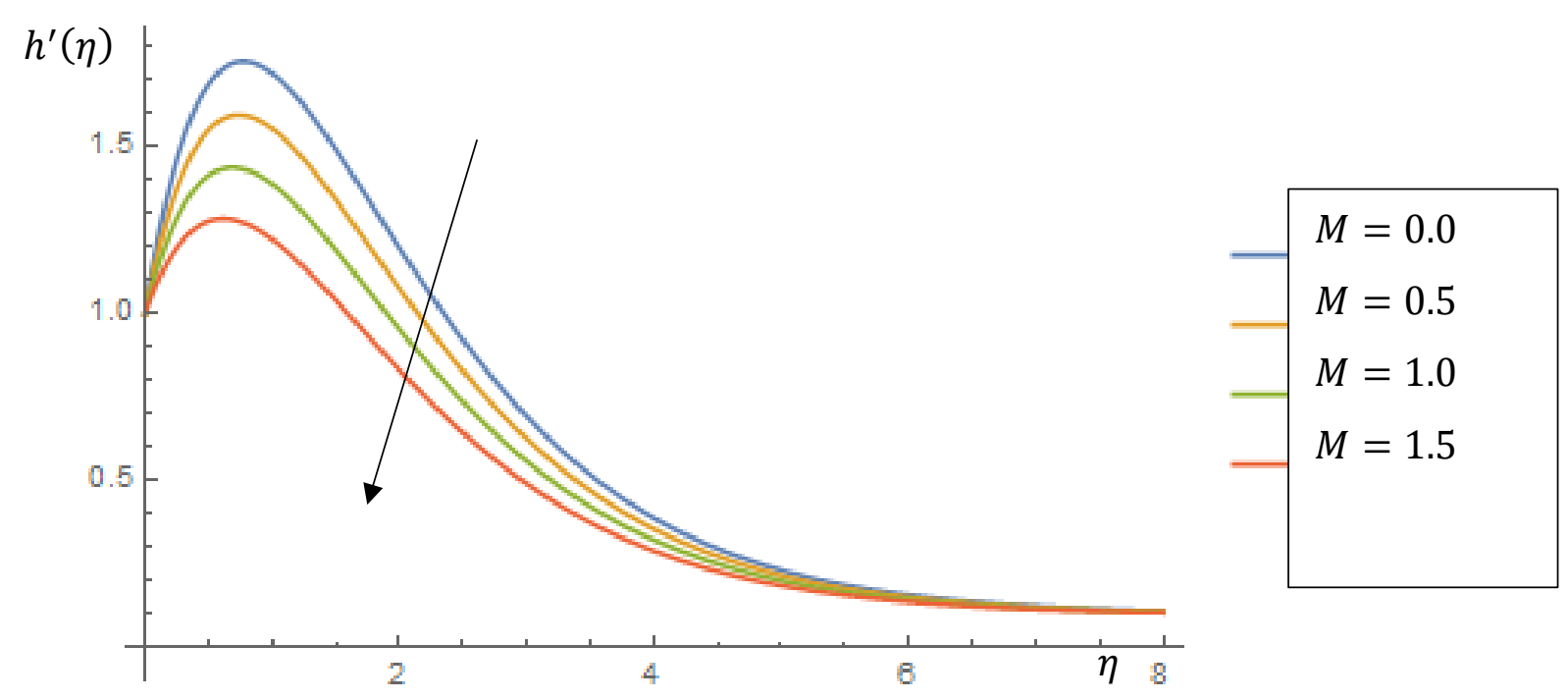

Figure 1: Impact of Magnetic factor $M$, on Velocity with

$$
\lambda=R=0.1, G r=5.0, \operatorname{Pr}=1.1
$$



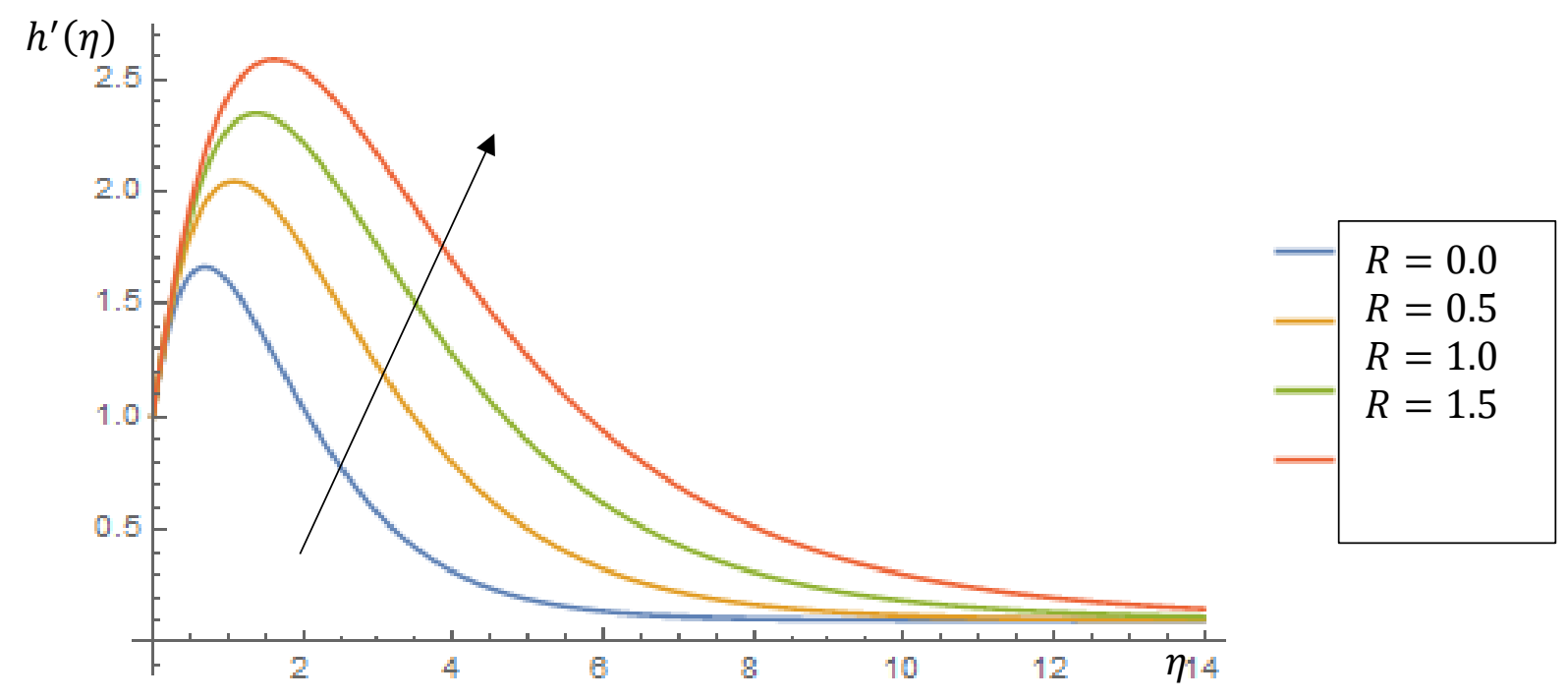

Figure 2: Impact of Radiation $R$, on Velocity with

$$
\lambda=M=0.1, \quad G r=5.0, P r=1.1
$$
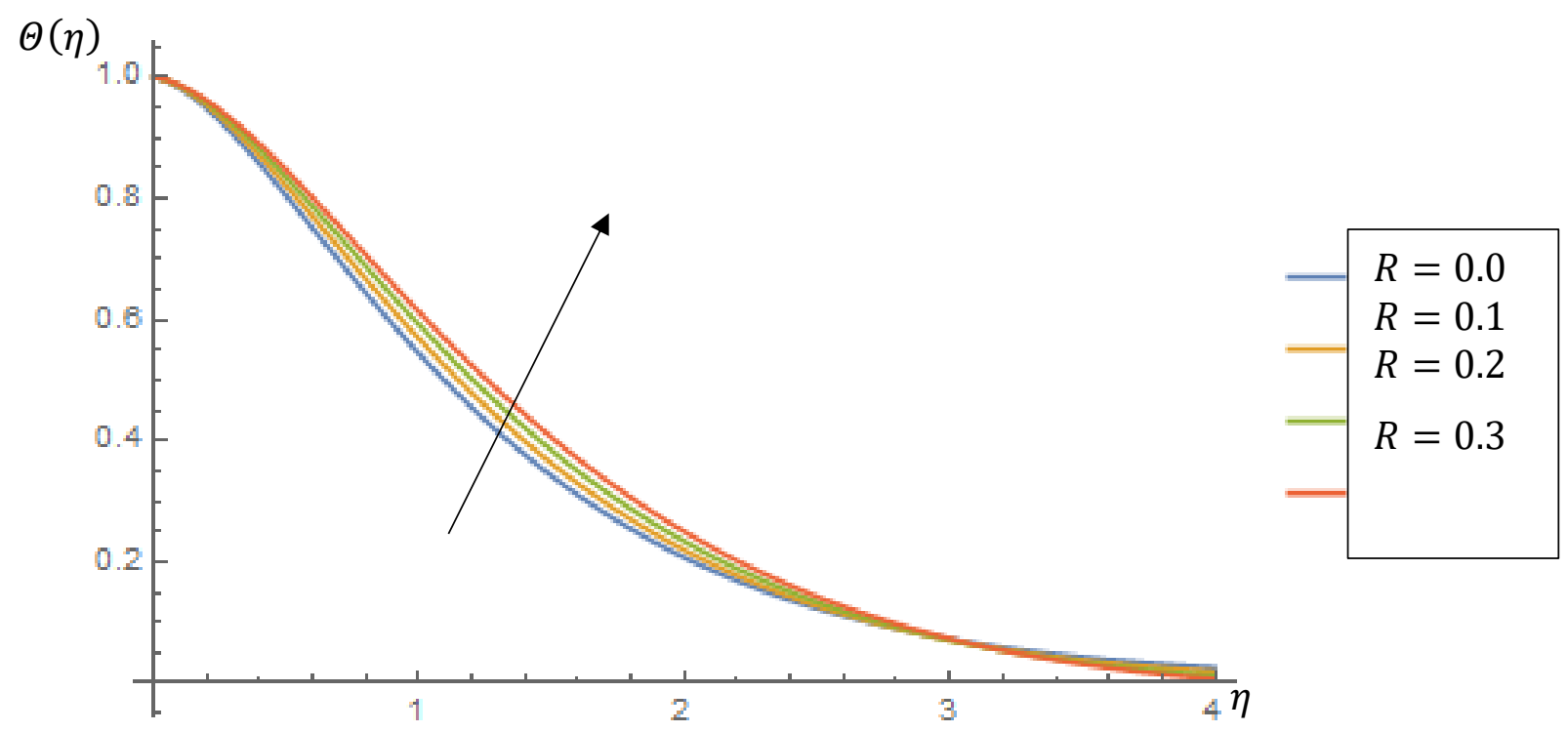

Figure 3: Impact of Radiation $R$, on Temperature with $S c=1.0$,

$$
N t=N b=\lambda=0.1, P r=1.1
$$




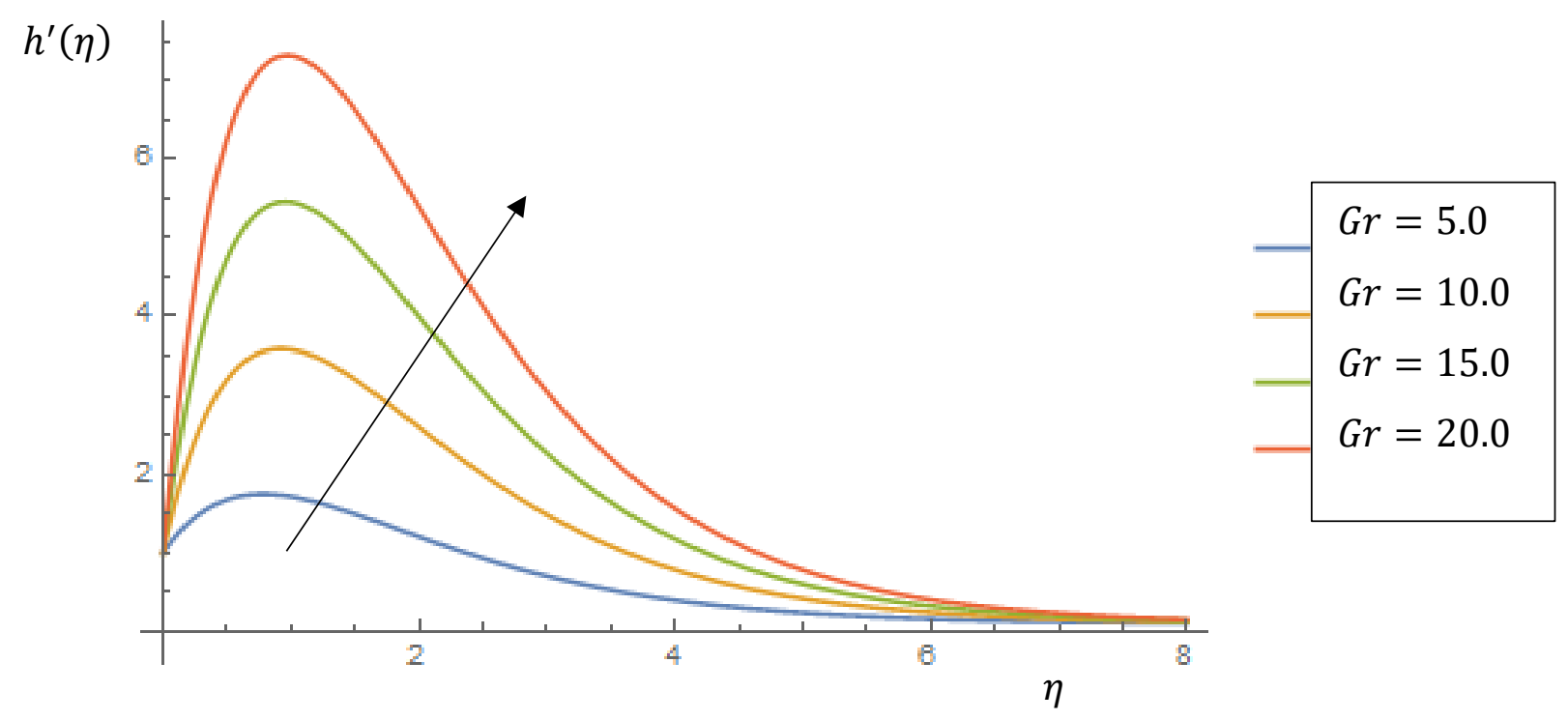

Figure 4: Impact of Modified Grashof number $G r$, on Velocity with $\lambda=R=0.1, M=0.1, P r=1.1$
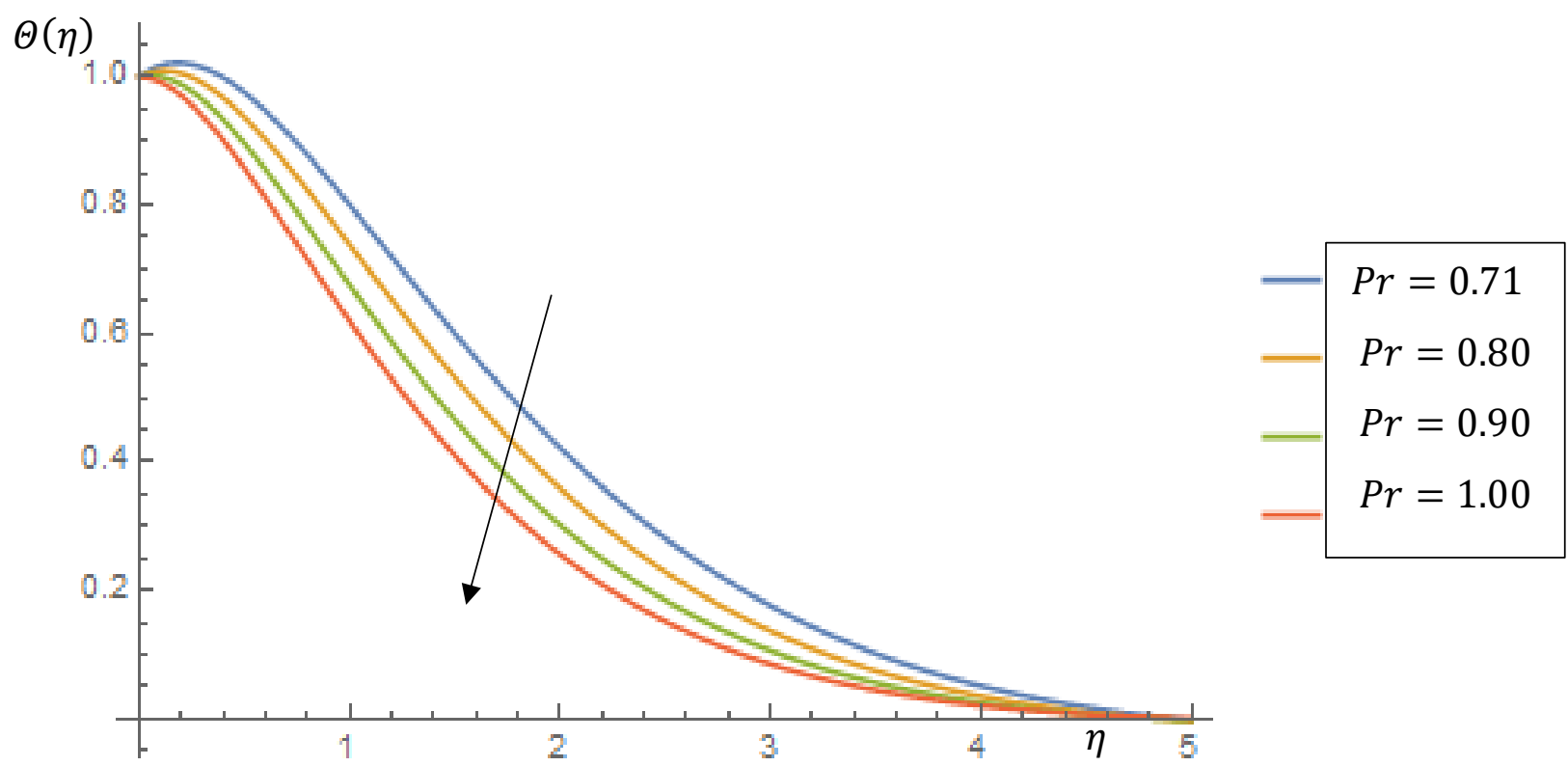

Figure 5: Impact of Prandtl Number $P r$, on Temperature with $S c=1.0, N t=R=\lambda=N b=0.1$ 


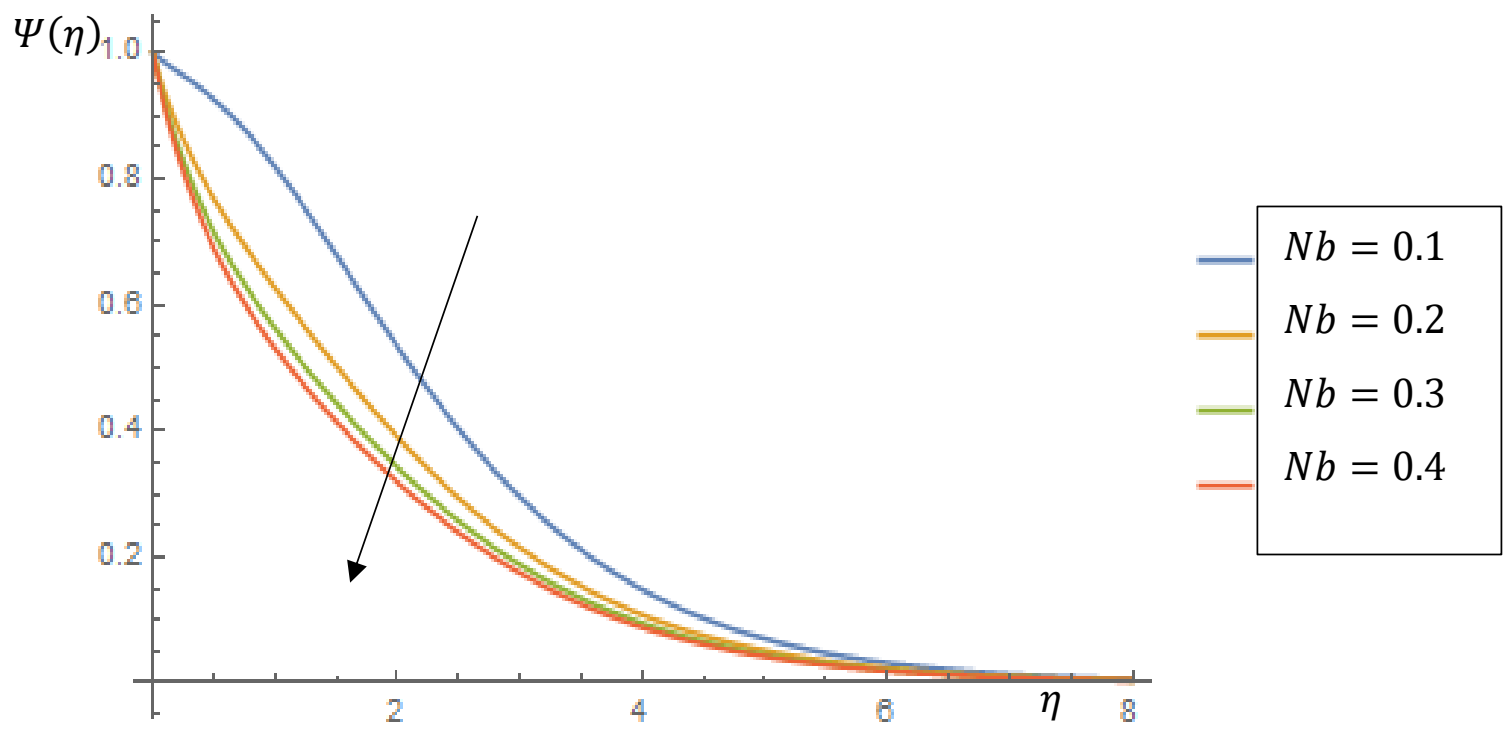

Figure 6: Impact of Brownian motion parameter $\mathbf{N b}$, on Concentration with $S c=1.0, \quad N t=\lambda=\gamma=R=0.1, P r=1.1$

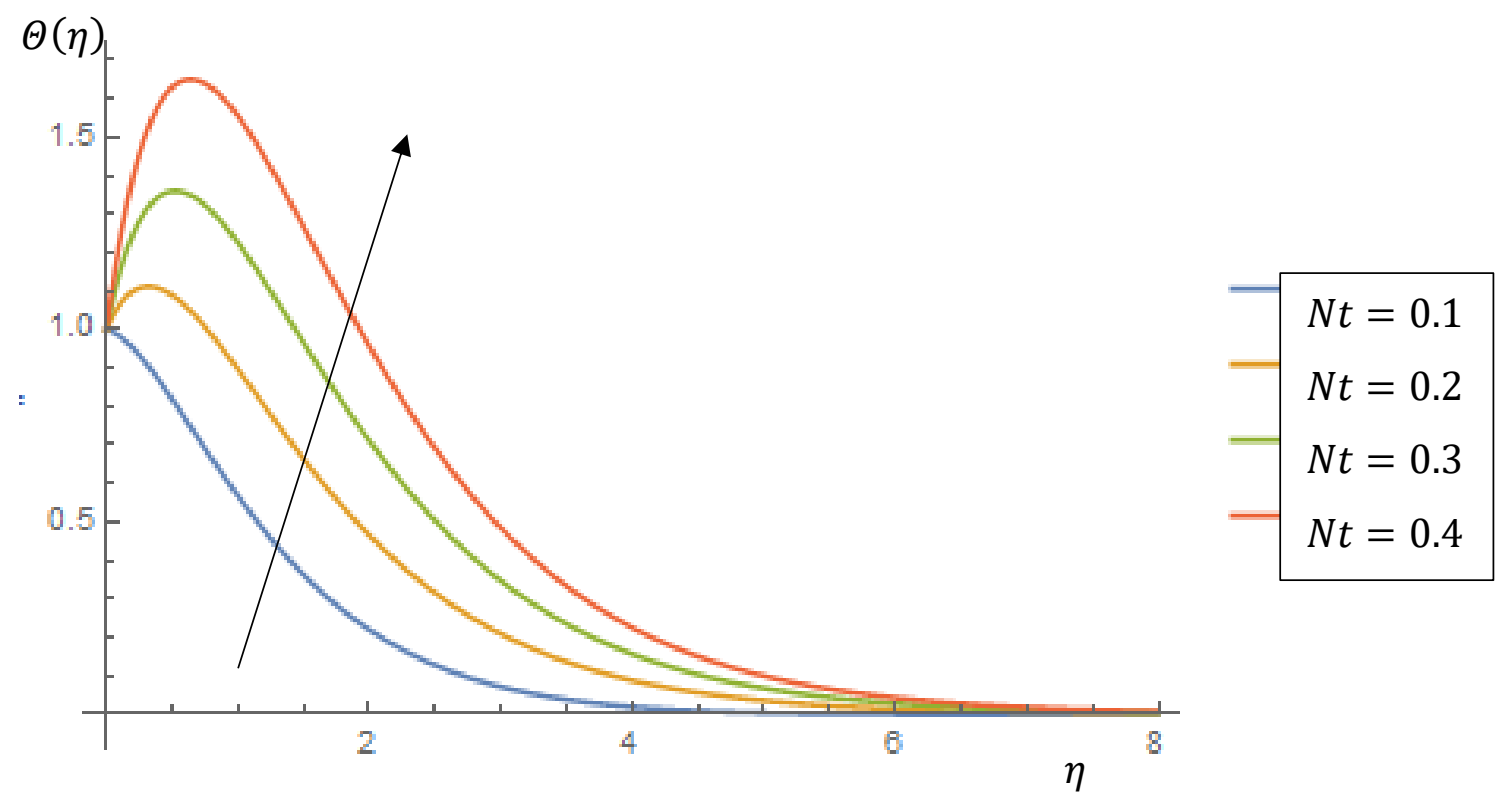

Figure 7: Impact of thermphoresis parameter $N t$, on Temperature with $S c=1.0, N b=R=\lambda=0.1, P r=1.1$ 


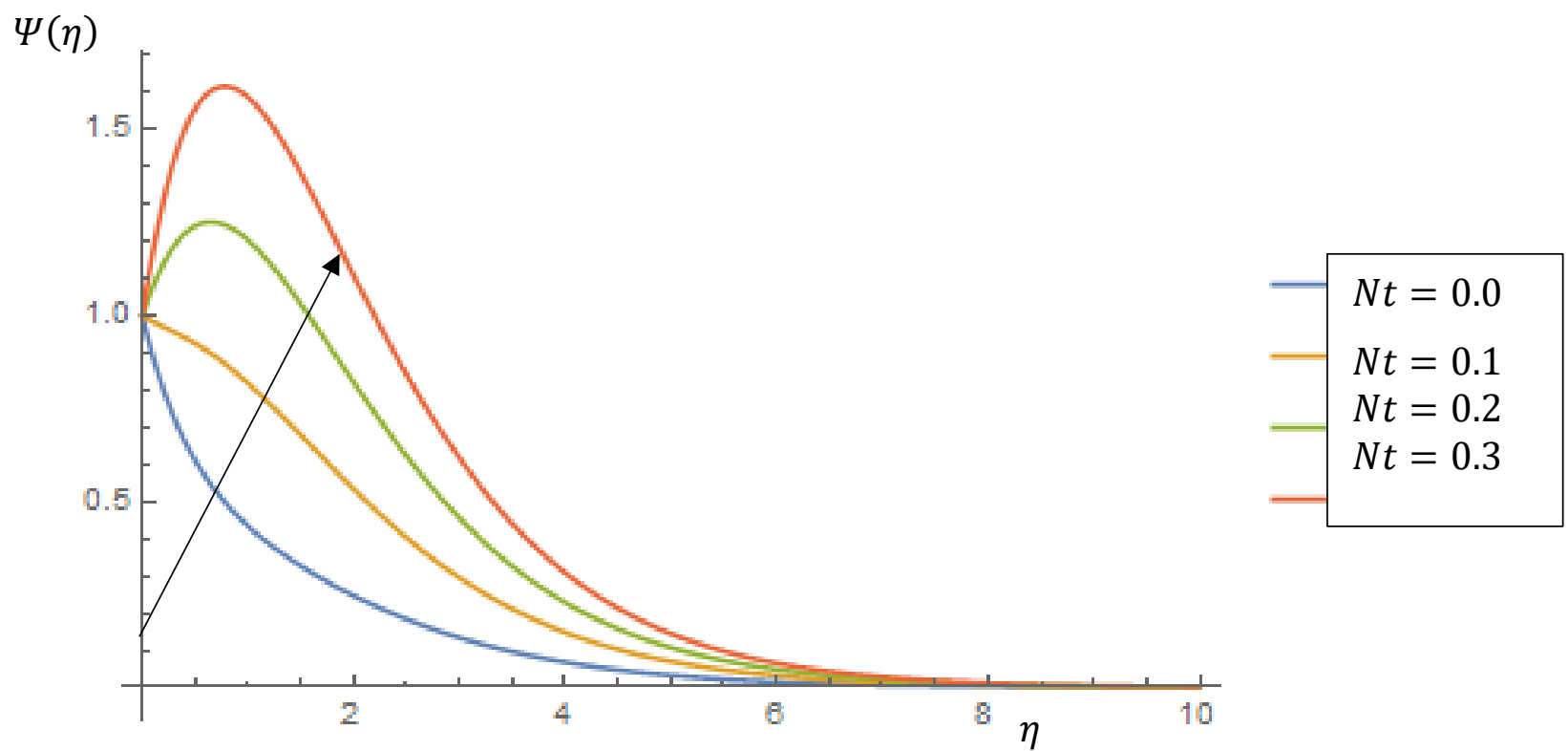

Figure 8: Impact of Thermophoresis parameter $N t$, on Concentration with $S c=1.0, N b=\lambda=\gamma=R=0.1, \operatorname{Pr}=1.1$

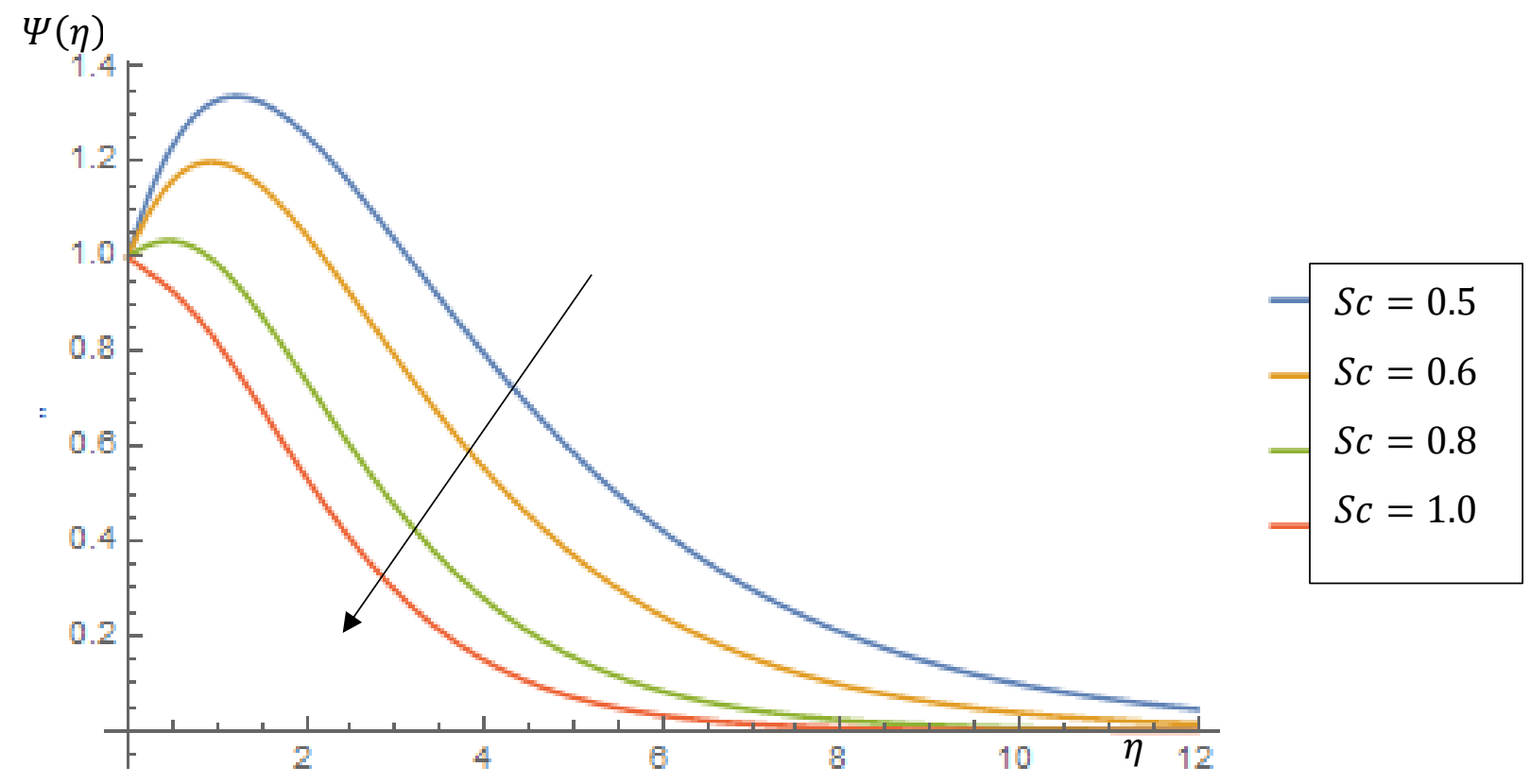

Figure 9: Impact of Schmidt number $S c$, on Concentration with $N b=N t=\lambda=\gamma=R=0.1, \operatorname{Pr}=1.1$ 


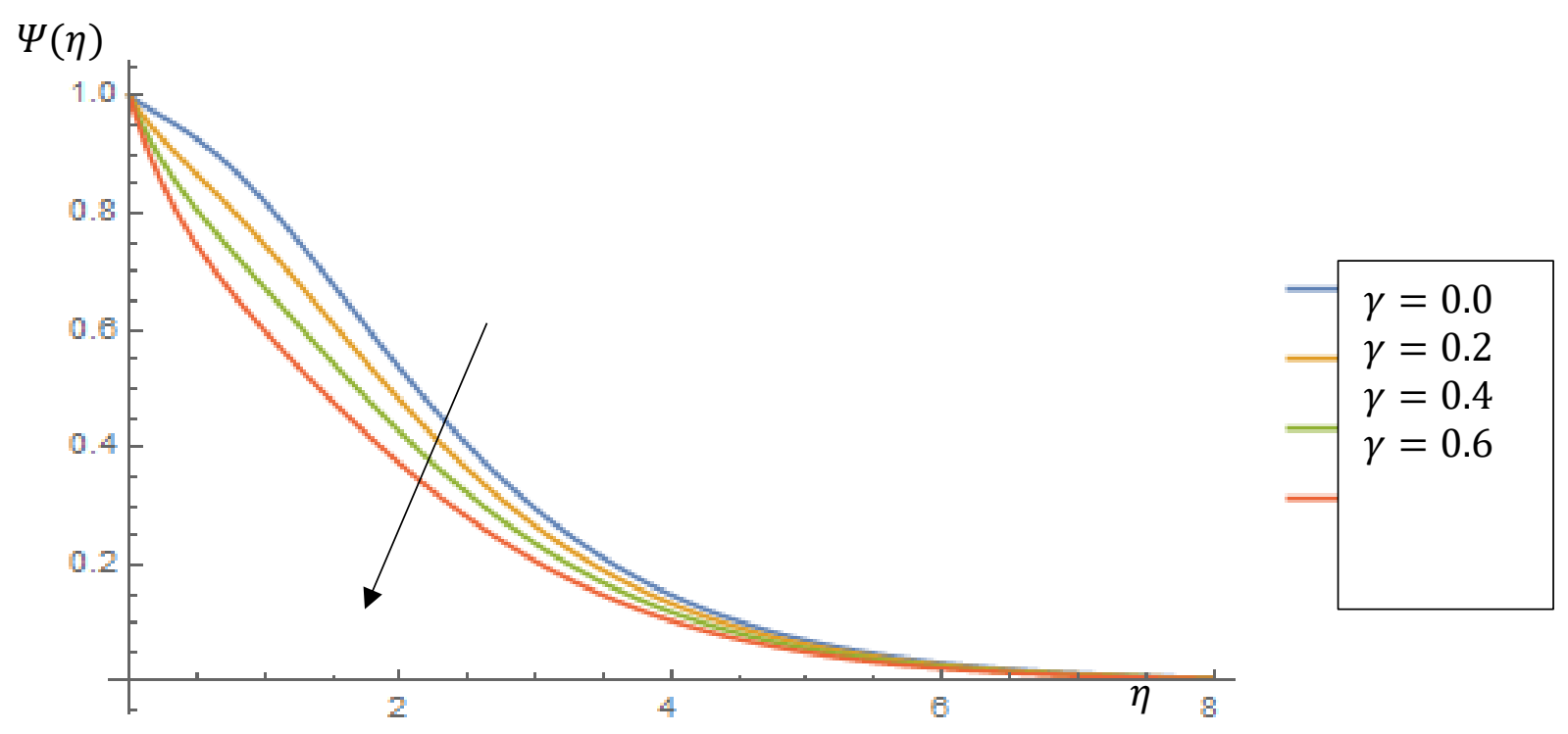

Figure 10: Impact of Rate of Chemical reaction parameter $\gamma$, on Concentration with $N b=N t=\lambda=R=0.1, \operatorname{Pr}=1.1, S c=1.1$

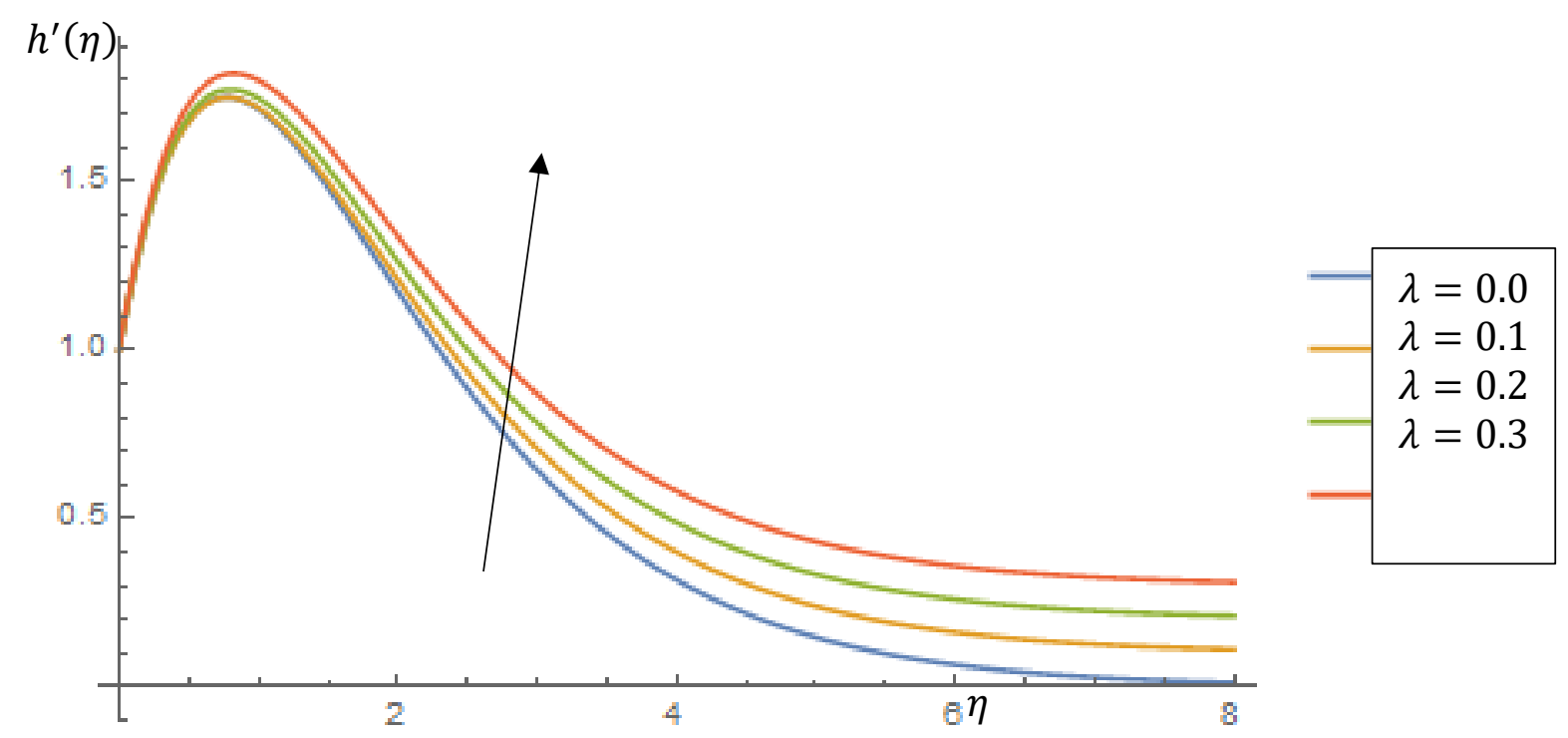

Figure 11: Impact of the stretching sheet parameter $\lambda$, on velocity with $M=R=0.1, G r=5.0, P r=1.1$ 


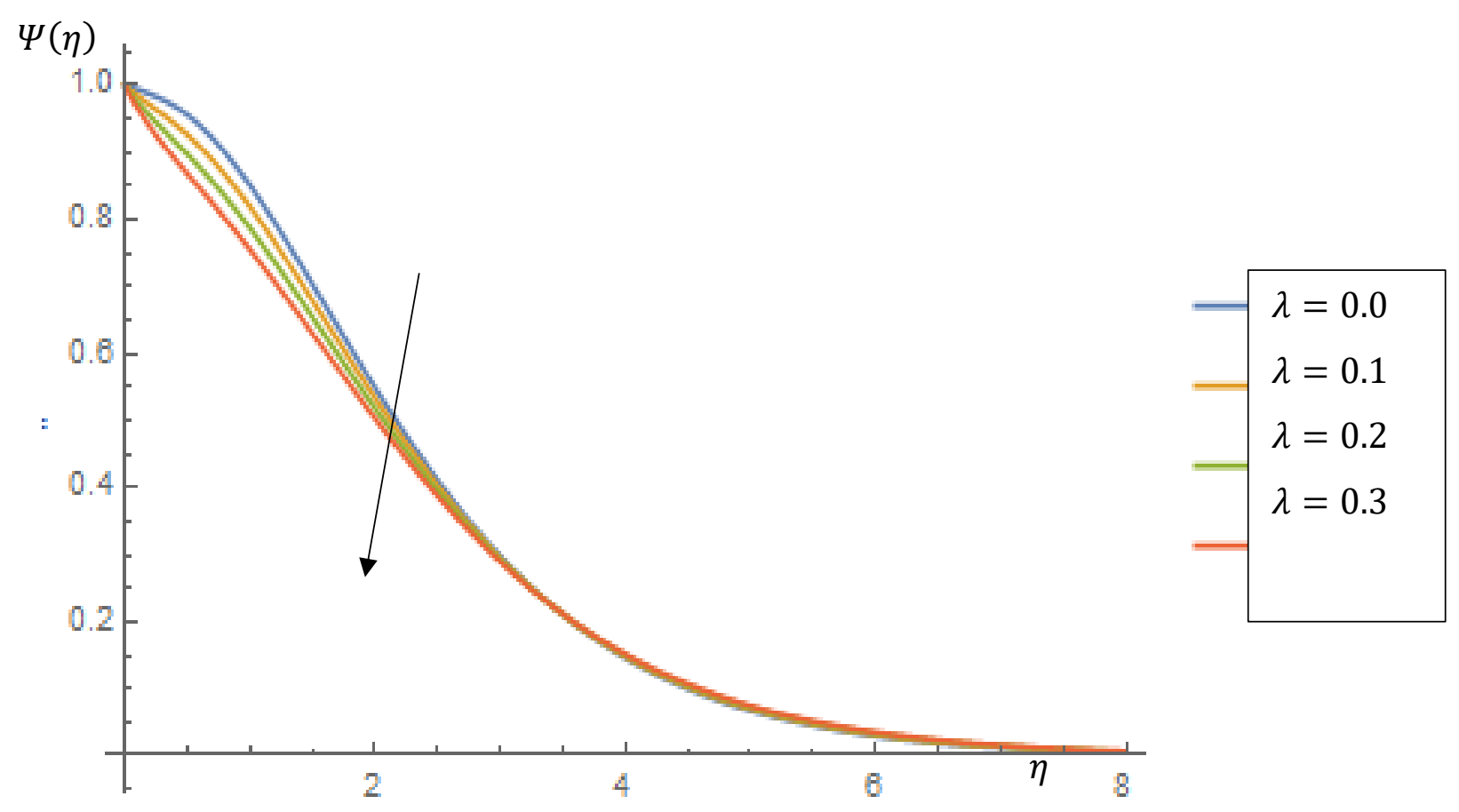

Figure 12: Impact of the stretching sheet parameter $\lambda$, on Concentration with $R=N t=N b=\gamma=0.1, G r=5.0, P r=1.1$.

\section{Discussion of Results}

The analysis of the fluid parameters involved in this study are presented as follows:

The vertical axis of the profiles with their corresponding legends are represented by $h^{\prime}(\eta), \Theta(\eta), \Psi(\eta)$ i.e., velocity, temperature and concentration while on the horizontal axis, we have $\eta$ in each case. Meanwhile, the legends displayed the effect of each parameter on the system. Thus, such impacts on the flow are discussed as follows:

The effect of magnetic strength $M$, on nanofluid motion is illustrated in figure 1 . The magnetic field produces an opposing strength termed Lorentz force that slows down boundary layer flow making the fluid movement to decrease as depicted in figure 1 . In order to bring the momentum development under control, the magnetic field is needed. Thus, depth of the momentum hydrodynamic reduces as magnetic parameter intensifies.

Figures 2 and 3 captures how radiation $R$ is affecting velocity and temperature distributions. Growing $R$, leads to enhancement in the rate of fluid passage. The reason being that high level of thermal energy which exists in form of heat generated through thermal radiation intensifies, the force (bond) binding the various components of the fluid particles together is weakened and in turn leading to the 
increase in fluid motion as depicted in figure 2. Similarly, the introduction of radiation in the path of the fluid motion means enhancing thermal radiation in and around the boundary and this entails surge in the boundary sheet thickness resulting in fluid temperature increase. This is illustrated in figure 3.

Figures 4 depicts the influence of thermal Grashof number $\mathrm{Gr}$, on velocity distribution. Physically, $G r$, is expressed as proportion of buoyancy to viscous forces and increasing its value within the momentum boundary layer, leads to increment in the buoyancy forces resulting to increase in velocity close to the sheet. This is due to the fact that closer to the sheet which radiates thermal energy in form of heat, the fluid molecules acquire more kinetic energy which makes them to be involved in more activity.

Significance of variations of Prandtl parameter $\mathrm{Pr}$, on temperature profile is well illustrated in figures 5. From this figure, it can be seen that higher values of Prandtl number $P r$, reduces the temperature thereby reducing the thermal boundary layer thickness. To support this phenomenon, we state that heat is diffused on heated sheet all through to the stretching sheet surface

The evolution of Brownian motion $\mathrm{Nb}$, on nano-particle concentration is given by figures 6 . When the value of $\mathrm{Nb}$ intensifies, a rapid movement of nanoparticles commence and this leads to a rise in acceleration which adds more energy to the particles, thus creating a fall in diffusion gradient of nanoparticles. This can be explained as the enhancement in $\mathrm{Nb}$ imparts on motion of particles of the fluid, in a way that such particles quickly migrate from areas of greater concentration towards areas of lesser concentration because of the fact that the nano-particle concentration decreases due to random motion of the particles.

Figures 7 and 8 entails the result of thermophoresis strength $N t$, on temperature and concentration distribution. The thermophoresis movement of nano-particles leads to the movement energy in flow region towards top of the stretching sheet. Thus, a decline in temperature gradient evolves as exhibited in figure 7. However, an increase in thermophoresis parameter $N t$, leads to a rise in concentration of particles. This is because intensifying thermophoresis parameter causes quick movement with the particles of the fluid flow which in turn brings about excess thermal energy inform of heat energy. Thus, this accounts for the high uprising of concentration profile.

Evolution on impact of $S c$, on concentration profile is displayed in figures 9. As a dimensionless number, $S c$ is expressed as a relation of momentum diffusivity (fluid viscosity) to mass diffusivity. However, when there is more fluid viscosity than heat energy and mass diffusivity, an intensification in the $S c$ occurs around boundary layer. Hence, a rise in Schmidt number lowers the concentration. The impact of rate of chemical reaction is illustrated by profile 10 . Increasing rate of chemical reaction is associated with a decay process in the thickness of the concentration boundary layer thereby causing decrease in its distribution.

The influence of stretching surface $\lambda$, on $h^{\prime}(\eta)$ and $\Psi(\eta)$ distributions are captured in figures 11 and 12 . Increasing the stretching sheet parameter $\lambda$ is 
accompanied with a rise in velocity shown in figures 11 . However, this may be attributed to the fact that the stretching sheet velocity is less than the free stream velocity. Thus, the fluid movement tends towards the free stream region near the surface of the plate. Also, from figure 12, the trend changes because enhancing $\lambda$, lowers, $\Psi(\eta)$. Hence, this accounts for decrease in concentration, because of the fact that particles are in constant migration.

\section{Conclusion}

In this work presently, we have made some important findings concerning the motion of fluid, temperature as well as concentration of nanoparticles in nanofluid. However, the system of equations describing the flow are cracked through analytical means through the application of asymptotic series technique with MATHEMATICA.

We also considered the impact of flow constraints and conclude as follows:

1. The impact of magnetic strength parameter on the fluid flow indicates a decline in velocity as the parameter increases while the reverse is the case when thermal Grashof, radiation and stretching factors rise.

2. As the values of Prandtl, Schmidt and stretching numbers upsurge, the temperature and concentration distributions decrease.

3. The effect of radiation and thermophoresis factors is observed as the intensification leads to a reduction in both the temperature and concentration of nanoparticles.

4. The concentration distributions decreases as the parameters for Brownian motion and rate of chemical reaction increase.

\section{Acknowledgement}

I want to acknowledge all my tutors for their sound tutoring and imparting of knowledge which has helped me in writing this academic research article.

\section{Nomenclature}

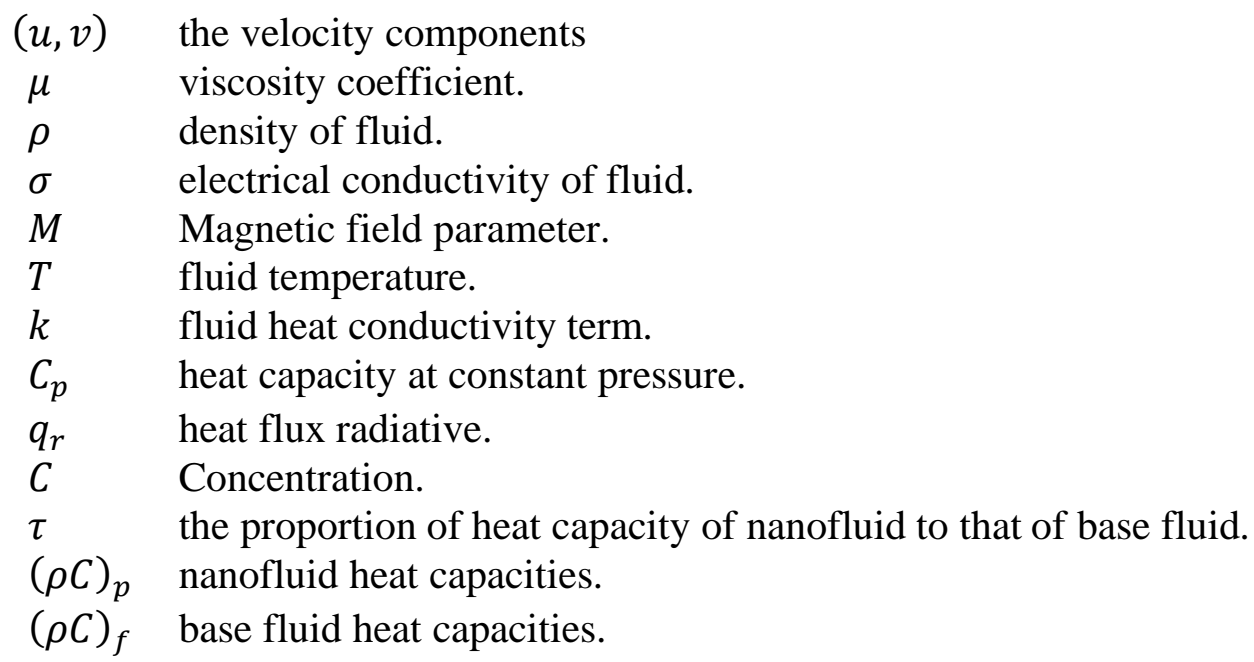


$D_{B} \quad$ Brownian motion coefficient.

$D_{T} \quad$ thermophoretic diffusion coefficient.

$T_{\infty} \quad$ ambient fluid temperature.

$C_{\infty} \quad$ ambient fluid concentration.

Pr Prandtl factor.

Sc Schmidt parameter.

$N t \quad$ thermophoresis number.

$\mathrm{Nb} \quad$ Brownian motion factor.

$\lambda \quad$ Stretching sheet velocity parameter.

$R \quad$ thermal radiation factor.

$\mathrm{Gr} \quad$ convective thermal Grashof factor.

$\mathrm{Gm}$ convective solutal Grashof factor.

\section{Statement Interest}

To the best of the authors knowledge, there's an absence of conflict of interest.

\section{References}

[1] Bouslimi, J., Abdelhafez, M. A., Abda-Alla, A. M., Abo-Dahab, S. M., and Mahmoud, K. H., (2021). Magnetohydrodynamic natural and forced Convection Nanofluid Flow past convectively Heated Nonlinear Stretching plate with Soret. Hindawi Complexity, Volume 2021, Article ID:5592024, 20 pages. https://doi.org/10.1155/2021/5592024.

[2] Bunonyo K. W., Amos E., and Eli I. C. (2018). Unsteady oscillatory Couette flow between parallel plates with constant radiative flux. Asian Research Journal of Mathematics, 11(2), 1-11.

[3] Chen, C. H., (1998). Laminar mixed convection adjacent to vertical, continuously stretching sheets. Journal of Heat and Mass Transfer, volume 33, Pages 471 - 476.

[4] Crane, L. J. (1970). Flow Past a Stretching plate. Journal of Applied Mathematics and Physics (JAMP), 21:645 - 647, doi:10.1007/BF01587695.

[5] Devi, R. and Reddy, N.B. (2014). Radiation in mass transfer effect on MHD boundary layer flow due to an exponentially stretching sheet with heat source. IJEIT, 3(8), 33-39

[6] Dandpat, B. S. and Chakraborthy, S. (2010). Effects of Variable fluid Properties on Unsteady thin film flow over a non-linear Extending surface. International Journal of Heat and Mass Transfer, 53, pp.5757-5763.

[7] Hsiao, K. L. (2011). MHD Stagnation Point Visco-elastic Fluid Flow and Heat Transfer on a Thermal Forming Stretching Sheet with Viscous Dissipation. Canadian Journal of Chemical Engineering 89, 1228-1235.

[8] Ishak, A., Nazar, R., and Pop, L. (2008). Hydromagnetic flow and heat transfer adjacent to a stretching vertical sheet. Journal of Heat and Mass, Vol. 44, pp. $921-927$. 
[9] Ibrahim, S. Y. and Makinde, O. D. (2010). Chemically reacting MHD layer flow of heat and mass transfer over a moving vertical plate with suction. Scientific Research and Essays Academic Journals, Vol. 5 (19), pp. 2875-2882. http://www.academicjournals.org/SRE. ISSN 1992-2248.

[10] Irfan, M., Farooq, A. M., and Razzaq, M. (2019). MHD free stream and heat Transfer of Nanofluid over an exponentially Radiating Stretching Sheeet with Variable Fluid Properties. Frontiers in Physics, 7:186, DOI: 10.3389/fphy.2019, 00186.

[11] Joaquin, Z. (2007). Network Simulation Method applied to Radiation and Viscous Dissipation Effects on MHD unsteady free convection over vertical porous plate. Journal of Applied Mathematical Modelling, Vol. 31(9), pp. 2019 - 2033. DOI:10.1016I/j.apm.

[12] Mabood F., Khan W. A., and IsmailA. I. Md (2017) MHD flow over an exponential radiating stretching sheet using Homotopy analysis method. J.Eng Sci, pp. 68-74.

[13] Makinde, O. D., Mabood, F., Kha, W., and Tshehla, M. S. (2016). MHD Flow of a Variable Viscosity Nanofluid over a Radially Stretching Convective Surface with Radiative Heat. Journal of Molecular Liquids, 219. DOI: 10.1015/j.molliq.2016.03.078.

[14] Nadeem, S., Haq, R., Akbar, N. S., and Khan, N. H., (2013). MHD threedimensional Casson Fluid flow past a porous linearly stretching sheet. Alexandira Engineering Journal, Vol.52, pp. 577 - 582.

[15] Oztop, H. F. and Abu-Nada, E. (2008). Numerical Study of Natural convection in Partially Heated Rectangular enclosures filled with nanofluid. International Journal of Heat Fluid Flow, Volume 29, Pages 1326-1336.

[16] Omamoke E., Amos E., and Bunonyo K. W. (2020). Radiation and heat source effects on MHD free convective flow over an inclined porous plate in the presence of viscous dissipation. American Journal of Applied Mathematics, 8(4), 190-206.

[17] Rohana, A. H. (2014). The Effect of Wall Suction/Injection on MHD Marangoni Convection Boundary Layer Flow in Nanofluid. AIP Conference Proceedings, vol. 1605, issue 1, pp.386; http://doi.org/10.1063/1.4887620.

[18] Raptis A., Perdikis C., and Takhar H. S. (2004). Effects of thermal radiation on MHD flow. Applications in Mathematics and Computations, 153, 645U648.

[19] Raju, M. C., Sandeep, N., and Malvandi, A. (2016). Free Convective heat and Mass Transfer of MHD non-Newtonian Nanofluids over a cone in the Presence of non-Uniform Heat Source/Sink. Journal of Molecular Liquids, 221. DOI: 10.1016/j.molliq.2016.05.078.

[20] Sakiadis, B. C. (1961). Boundary layer behavior on continuous solid surfaces. AlchJ, PP. 26 - 28.

[21] Santoshi, M. and Govardhan, K. (2020). Effect of Magnetic Field, Heat Generation and Absorption on Nanofluid Flow Over a Nonlinear Stretching Sheet. BEILSTEIN Journal of Nanotechnology, Vol. 11, pages 976-990. Doi:10.3762/bjnano.//.82. 
[22] Sheremet, M. and Pop, L. (2014). Natural Convection in a wavy porous cavity with sinusoidal Temperature distributions on Both side walls filled with a Nanofluid: Buongiorno's Mathematical Model:10.1007/511242-014-0375-7. License. CC BY 4.0

[23] Sheremet, M. A. and Pop, L. (2015). Free convection in a triangular cavity filled with a porous medium saturated by a nanofluid Buogiorno's mathematical model. International Journal of Numerical Methods for Heat and fluid flow, vol. 25, Issue 5, pp. 1138 - 1161. http://dx/doi.org/10.1108/HFF06-2014-0181.

[24] Seini, Y. I. (2013). Flow Over Unsteady Stretching Surface with Chemical Reaction and non-uniform Heat Source. Journal of Engineering and Manufacturing Technology., 1 (2013) 24-35.

[25] Seini, Y. I. and Makinde, O. D. (2013). MHD Boundary Layer Flow due to Exponential Stretching Surface with Radiation and Chemical Reaction. Mathematical Problems in Engineering, Volume 2013, Article ID 163614, pp. 1-7.

[26] Sahoo, A. C., and Biswal, T. (2015). MHD Visco-elastic Boundary Layer Flow Past a Stretching Plate with Heat Transfer. IJEMAS, vol. 3(9), 11-18.

[27] Wikipedia, the Free Encyclopedia, 2017. 